\title{
Early diagnosis of health damage in arc welders based on their serum ferritin level
}

\author{
Kazuaki Sera', Yoshihiro Nishimura ${ }^{2}$, Chiyo Hayashi ${ }^{3}$, Hisahide Nishio ${ }^{3}$ \\ ${ }^{1}$ Hyogo Occupational Health Promotion Center, Kobe, Japan; \\ ${ }^{2}$ Division of Respiratory Medicine, Department of Internal Medicine, Kobe University Graduate School of Medicine, Kobe, Japan; \\ ${ }^{3}$ Division of Public Health, Kobe University Graduate School of Medicine, Kobe, Japan. \\ Email: mailto:nishiy@med.kobe-u.ac.jp
}

Received 31 August 2011; revised 15 September 2011; accepted 18 October 2011.

\begin{abstract}
To develop a method for the early diagnosis of health damage due to arc welding, we measured serum ferritin in 96 general employees and 320 arc welders in Company A. A positive correlation was observed between age and the serum ferritin level in the young group (age, 20 - 44 years) among the general employees. The mean serum ferritin level in the general employees was $119 \pm 56 \mathrm{ng} / \mathrm{ml}$. When the mean $\pm 2.5 \mathrm{SD}$ was used as the standard value, ferritin levels $>260$ $\mathrm{ng} / \mathrm{ml}$ could be regarded as high. Based on this standard value, high ferritin levels were observed in 7 (6.6\%) of 106 young arc welders in Company A but none of the general employees. Chest $\mathrm{X}$-ray films showed minimal abnormality in one of 7 young arc welders who showed high ferritin levels. These results suggest that the determination of the serum ferritin level is useful for the early diagnosis of health damage due to arc welding.
\end{abstract}

Keywords: Ferritin; Arc Welder; Pneumoconiosis; Checkup

\section{INTRODUCTION}

Arc welder's lung is a lung disorder observed in arc welders. It is considered to be a type of industrial accident in Japan and a disease to which the Pneumoconiosis Law is applied. Currently, in Japan, strict measures are taken to prevent the development of arc welder's lung, and instructions are also given by the Ministry of Health, Labor and Welfare.

We recently encountered a 58-year-old male with arc welder's lung, which was the motive for performing this study [1]. This man had worked as an arc welder for 40 years since he was 18 years old. In December 1999, he was engaged in the removal of iron boards in tunnels and noticed dyspnea after working for 20 days. This work is called "gouging" and is performed by arc welding. Chest $\mathrm{X}$-ray examination showed pulmonary fibrosis. Analysis of cell fractions of bronchoalveolar lavage fluid showed $79.6 \%$ macrophages, of which about $83 \%$ were positive for iron staining. Transbronchial lung biopsy revealed localized intra-alveolar fibrosis and alveoli filled with iron staining-positive macrophages that had phagocyted a dark brown substance suggesting hemosiderin. Blood tests showed an abnormally high serum ferritin level (2300 ng $/ \mathrm{ml})$. The serum ferritin level continued to increase for the subsequent few years.

Based on the findings in this patient, we speculated that the measurement of serum ferritin allows the early confirmation of health damage due to arc welding, and performed this study.

\section{MATERIAL AND METHODS}

\subsection{Study Population and Laboratory Data}

The subjects were 320 arc welders and 96 general employees in a company (Company A) from which cooperation was obtained. Two items (serum ferritin and serum iron) were added to the blood analysis items in the general health checkup examination. In this company, masks are always used during arc welding, and the working environment, such as ventilation, was adequate.

\subsection{Informed Consent}

Oral consent was obtained from the subjects, and blood for serum ferritin analysis was collected simultaneously with blood collection for the analysis of other items in a periodical health examination. The current study was conducted in accordance with the recommendations outlined in the Declaration of Helsinki.

\subsection{Statistical Analysis}

The data were analyzed for inter-group differences in plasma ferritin concentration with Mann-Whitney's U test. All data were analyzed with StatView version 5.0 for 
Macintosh. All data are reported as the mean \pm SD. A two-tailed value of $\mathrm{p}<0.05$ was considered significant.

\section{RESULTS}

Figure 1 shows the distribution of serum ferritin levels observed in Company A. The mean ferritin level did not significantly differ between the general employees (119 $\pm 56 \mathrm{ng} / \mathrm{ml})$ and the arc welders $(138 \pm 91 \mathrm{ng} / \mathrm{ml})$. In the general employees, a slight age-related increase was observed (Figure 1(a)). In the arc welders, unlike the general employees, the serum ferritin level was often low in aged welders but high in some welders in the young group aged 20 - 44 years (Figure 1(b)).

The mean ferritin level $\pm 2.5 \mathrm{SD}$ in the general employees was calculated, and the normal limit was determined to be $260 \mathrm{ng} / \mathrm{ml}$. In the young general employee group, none showed a serum ferritin level above this normal limit. However, some arc welders showed high serum ferritin levels (highest, $702 \mathrm{ng} / \mathrm{ml}$ ). In the young arc welder group $\leq 40$ years, 7 (6.6\%) of 106 welders showed a high serum ferritin level, and the incidence signifycantly differed between this group and the young general employee group $\left(\chi^{2}\right.$ test, $\left.\mathrm{p}<0.05\right)$. Thus, in the young

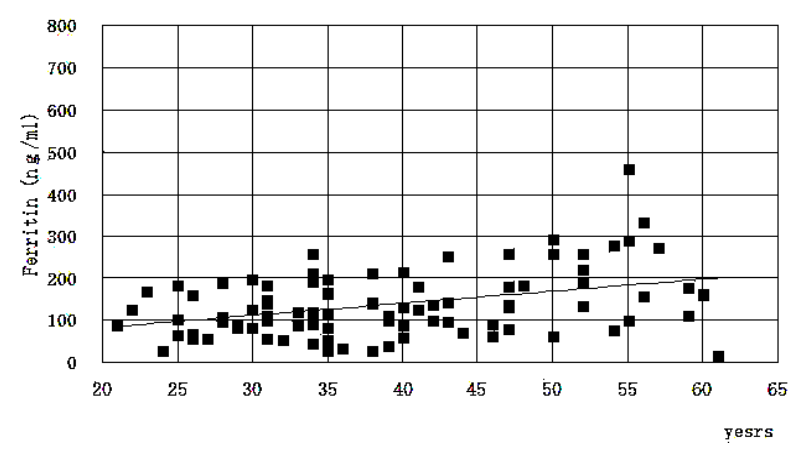

(a)

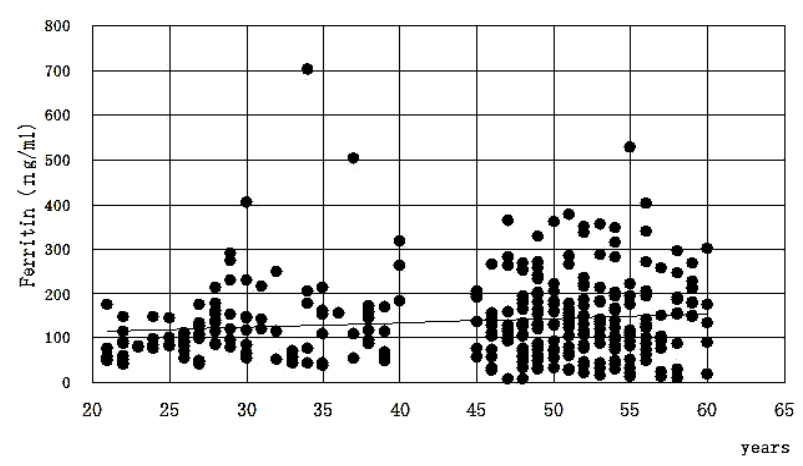

(b)

Figure 1. Relationship between serum ferritin concentration and age in the A company. Serum ferritin concentrations were determined by using a commercially available immunoassay kit. Data were analyzed by a simple linear regression $A$; normal controls $(r=0.383, p<0.01)$, B; welders $(r=0.123$, $p=$ 0.01). group, some showed high serum ferritin levels estimated to be observed in arc welders. There was only one subject who showed chest X-ray abnormality in these 7 young arc welders. Chest $\mathrm{X}$-ray examination at the periodical health examination showed minimal abnormal findings in 11 of 320 arc welders. However, there was no significant difference in serum ferritin level between arc welders with and without abnormalities of chest X-ray examinations.

The serum iron level did not significantly differ between the general employees (112 $\pm 36 \mathrm{ng} / \mathrm{ml})$ and the arc welders (115 $\pm 40 \mathrm{ng} / \mathrm{ml})$.

\section{DISCUSSION}

The welding process consists of several steps. Though the fumes generated differ among the steps, at least 13 metals (such as $\mathrm{Fe}, \mathrm{Cr}, \mathrm{Co}, \mathrm{Zn}, \mathrm{Cd}, \mathrm{Mn}, \mathrm{Be}, \mathrm{Hg}$, and $\mathrm{Pb}$ ) are considered to be involved [2]. Based on an abnormally high serum ferritin level observed in a welder, we evaluated the ferritin level in welders in this study. Ferritin as well as transferrin is physiologically important for iron metabolism. Ferritin is a protein with a molecular weight of 430,000 - 450,000 and can contain 1200 iron atoms. Ferritin is distributed in each human organ as well as the blood and is particularly found in large amounts in the liver and spleen but is also present in the lungs. Ferritin stores iron and is also used as a clinical tumor marker.

In arc welder's lung, an increase in the serum ferritin level has been reported [3,4]. Yoshii et al. reported a significantly higher ferritin level in the bronchoalveolar lavage fluid in welder's pneumoconiosis than in welder's lung before the stage of pneumoconiosis, pneumocilicosis, or pulmonary asbestosis. They also reported the usefulness of the serum ferritin level and BAL ferritin level for the diagnosis of arc welder's lung [5]. Ferritin is considered to increase because inhaled iron is phagocyted by alveolar macrophages and stored as ferritin in the alveoli. The increase in the serum ferritin level in arc welder's lung may be due to the synthesis of ferritin from the iron powder in alveolar macrophages. In healthy adults, ferritin has been reported to increase with age, which was consistent with the findings in this study.

Lu et al. recently evaluated serum ferritin in welders [6] and observed an association between the years of welding experience and the plasma ferritin level. They also evaluated transferrin receptors and observed its decrease in welders, and suggested its association with an increase in plasma magnesium. These results are interesting in terms of the understanding of metabolism.

In this study, some arc welders showed a serum ferritin level higher than that in the general employees. In these employees in Company A, chest X-ray examination showed only slight abnormalities in the lung fields. 
An increase in the serum ferritin level may be a blood examination abnormality prior to chest X-ray findings. These findings suggest that the measurement of serum ferritin allows the early detection of arc welding-associated health damage prior to the development of arc welder's lung in some cases. Further long-term observation is necessary.

\section{CONCLUSIONS}

Our results suggest the usefulness of the measurement of serum ferritin in the early diagnosis of health damage due to arc welding.

\section{REFERENCES}

[1] Ishida, Y., Sera, K., Ohta, K. and Kageshita, T. (2003) A case of rapid development of arc welder's lung during the course of a year. Nihon Kokyuki Gakkai Zasshi, 41, 351-355.

[2] OSHA (1995) Metal and metalloid particulates in workplace atmospheres (ICP Analysis). http://www.osha.gov/dts/sltc/methods/inorganic/id125g/i d125g.pdf

[3] Yoshii, C., Matsuyama, T., Takazawa, A., et al. (2002) Welder's pneumoconiosis: Diagnostic usefulness of highresolution computed tomography and ferritin determinations in bronchoalveolar lavage fluid. Internal Medicine, 41, 1111-1117. doi:10.2169/internalmedicine.41.1111

[4] Kinoshita, M., Hanzawa, S., Momiki, S., et al. (1997) A case of pneumoconiosis (welder's lung) suspected to be lung cancer. Nihon Kyobu Shikkan Gakkai Zasshi, 35, 1124-1131.

[5] Yamada, G., Igarashi, T., Sonoda, H., et al. (1998) Use of bronchopulmonary lavage for eliminating inhaled fume particles from a patient with arc welder's lung. Internal Medicine, 37, 962-964. doi:10.2169/internalmedicine.37.962

[6] Lu, L., Zhang, L., Li, G.J., Guo, W., Liang, W. and Zheng, W. (2005) Alteration of serum concentrations of manganese, iron, ferritin, and transferrin receptor following exposure to welding fumes among career welders. Neuro Toxicology, 26, 257-265.

doi:10.1016/j.neuro.2004.09.001 